\title{
Sildenafil citrate and uteroplacental perfusion in fetal growth restriction
}

\author{
Priya Singh, Hena Saiyda*
}

Department of Obstetrics and Gynecology, MRA Medical College, Ambedkarnagar, Uttar Pradesh, India

Received: 15 October 2018

Accepted: 27 October 2018

\section{*Correspondence:}

Dr. Hena Saiyda,

E-mail: henasaiyda@gmail.com

Copyright: (C) the author(s), publisher and licensee Medip Academy. This is an open-access article distributed under the terms of the Creative Commons Attribution Non-Commercial License, which permits unrestricted non-commercial use, distribution, and reproduction in any medium, provided the original work is properly cited.

\begin{abstract}
Background: Severe early-onset fetal growth restriction can lead to a range of adverse outcomes including fetal or neonatal death, neurodisability, and lifelong risks to the health of the affected child. Sildenafil, a phosphodiesterase type 5 inhibitor, potentiates the actions of nitric oxide, which leads to vasodilatation of the uterine vessels and might improve fetal growth in utero. The objective is to evaluate effectiveness and safety of Sildenafil citrate for treatment of Doppler velocimetry of uterine, umbilical artery for systolic/diastolic ratio (S/D ratio) at first visit, after 2 hours and then after 12 weeks of treatment.

Methods: A case control study was carried out in 96 antenatal women with fetal growth restriction over a period of twelve months. A written informed consent was obtained. Out of 96, 12 were lost to follow up. Of remaining 84 women, 42 were included in the study group and 42 in the control group. First group (case) received Sildenafil citrate $50 \mathrm{mg}$ stat followed by colour Doppler after 2 hours and then $25 \mathrm{mg}$ three times a day for 12 weeks. The second group (control) received placebo in for 12 weeks.

Results: Sildenafil treatment was associated with a significant increase in length of pregnancy $(\mathrm{P}>0.05)$ overall mean S/D ratio pre-sildenafil was $5.34 \pm 0.93$ which reduced to $5.18 \pm 0.95$ after 2 hours of sildenafil administration and this significant was highly significant $(\mathrm{p}<0.0001)$.and also the mean S/D ratio pre-treatment was $6.72 \pm 0.38$ which decreased to $3.52 \pm 0.47$ after 12 weeks of sildenafil administration. The difference between them was found to be extremely significant $(\mathrm{p}<0.0001)$.

Conclusions: Sildenafil citrate can improve utero-placental perfusion and length of pregnancy in pregnancies complicated by IUGR. It appears to have a significantly positive effect on fetal weight. Sildenafil treatment may offer a new opportunity to improve perinatal outcomes, for pregnancies complicated by IUGR. However, these observations require further studies on wide scale.
\end{abstract}

Keywords: Fetal growth restriction, Sildenafil citrate, Uteroplacental perfusion

\section{INTRODUCTION}

During pregnancy, transport of nutrients from the mother to the fetus is primarily dependent on uteroplacental blood flow, which enhances significantly during the second and third trimesters of gestation. ${ }^{1,2}$ Fetal growth restriction (FGR) creates complications in $7-15 \%$ of pregnant women, and in its early and severe form, the risk of perinatal morbidity and mortality is increased. ${ }^{3}$
Because of the significance of placental blood flow to placental function and the recognition that placental size, uteroplacental blood flows, and appearance of angiogenic and vasoactive factors are reduced or altered in compromised pregnancies, it has been suggested that therapeutic agents that target placental blood flow might be used to ameliorate FGR. ${ }^{4}$ Several new vasodilator drugs have freshly been recommended to augment blood flow to tissues, and one of these drugs is sildenafil citrate 
(SC) (Viagra). ${ }^{4} \mathrm{SC}$ is a selective inhibitor of cyclic guanosine monophosphate formation through inhibition of type-5 phosphodiesterase (PDE5). ${ }^{4}$ It increases uterine blood flow and potentiates estrogen-induced vasodilatation..$^{5}$ A number of studies postulated that SC may offer a potential therapeutic strategy to improve uteroplacental blood flow in FGR pregnancies. ${ }^{6-8}$ It has been imagined that the PDE5 inhibitor may be useful in the treatment of hypertension during pregnancy as well as FGR. Sildenafil improves endothelial function of myometrial vessels in women whose pregnancies are complicated by FGR and induces vasodilation of chorionic plate arteries in women with normal pregnancies. ${ }^{9}$ The present study was undertaken to diagnose as early as possible fetal growth restriction and provide early intervention in the form of administering sildenafil citrate to these patients with an aim to diagnose fetal growth restriction between 24-37 weeks of gestation, confirm gestational period and fetal growth restriction and to study Doppler velocimetry of uterine, umbilical artery for systolic/diastolic ratio (S/D ratio) at first visit, after 2 hours and then after 12 weeks of treatment.

\section{METHODS}

The study was carried out in 96 antenatal women with fetal growth restriction attending the outpatient department and inpatients over a period of twelve months during the year 2014-2015. Conducted in collaboration with the department of radiodiagnosis of Swarooprani Nehru hospital and Kamla Nehru memorial Hospital. All the antenatal women with diagnosed fetal growth restriction were divided into two groups. First group (cases) received Sildenafil citrate $50 \mathrm{mg}$ stat followed by colour Doppler after 2 hours and then $25 \mathrm{mg}$ three times a day for 12 weeks. The second group (control) received placebo in for 12 weeks. A written informed consent was obtained from all subjects prior to the performance of any study related procedure. The study was approved by the ethical committee of institute.

\section{Inclusion criteria}

- Gestational age 24-37 weeks with singleton pregnancy

- Antenatal women with willingness to sign informed consent for study randomization

- Pregnancies with no known congenital anomaly in the fetus.

- Eligibility to be offered sildenafil-no major medical illness including cardiovascular disease or diabetes mellitus.

\section{Exclusion criteria}

- Pregnancies less than 24 weeks of gestation

- Any known congenital defect in the fetus

- Multiple pregnancy

- Inability to present for monitoring visits
- Any major medical illness, including cardiovascular disease and diabetes mellitus

- Inability to follow medication instruction

- Reversed umbilical arterial end diastolic flow in Doppler

- Refusal to undergo Doppler studies or to undergo sildenafil treatment.

Control group: Antenatal women of same age group, gestational age and following the inclusion and exclusion criteria as described above.

A detailed clinical history was taken with special reference to age, gravida-parity, gestational age, socioeconomic status and education.

Group I (SC group): this group consisted of 44 women who received single oral dose of $50 \mathrm{mg} \mathrm{SC}$.

Group II (placebo group): this group consisted of 52 women who received single oral dose of placebo.

Medications were administered by double-blinded criteria, with both sildenafil and placebo tablets having an identical appearance.

\section{RESULTS}

The cases in study group received oral sildenafil citrate $50 \mathrm{mg}$ after ultrasonography and Colour Doppler flow velocimetry and then Doppler flow velocimetry was repeated after 2 hours. The cases then received oral 25 $\mathrm{mg}$ sildenafil citrate thrice daily for a period of 12 weeks or till termination of pregnancy, whichever occurred earlier. Similarly, the cases in control group received placebo and repeat colour Doppler was done after 2 hours and then placebo treatment was continued for a period of 12 weeks.

All cases included in the study were in the age group of 16-35 years. The mean age of cases was $25.88 \pm 4.145$ and $25.7 \pm 3.623$ years respectively. Maximum number of cases were primigravidae; $17(40 \%)$ in study group and $15(35 \%)$ in control group. There were $8(20 \%)$ second gravida in study group and $11(27 \%)$ in control group. Third and fourth gravida in study group were $11(27 \%)$ and $5(13 \%)$ casesrespectively. In control group $10(23 \%)$ cases were third gravida and $4(10 \%)$ cases were fourth gravida. Cases with greater than or equal to fifth gravidity were $1(2 \%)$ and $2(5 \%)$ in study and control groups respectively. The mean gravidity in study group was $2.1 \pm 1.3$ compared to $2.2 \pm 1.24$ in control group. In the study group, $23(55 \%)$ cases were from urban residential area and $19(45 \%)$ from rural area. In the control group, $20(48 \%)$ cases were from urban and $22(52 \%)$ from rural area. $76.1 \%$ of cases in the study group were literate while $66.6 \%$ cases in the control group were literate. In the study group $23.8 \%$ and in the control group $33.3 \%$ cases were illiterate. In the study group, only $6(14.2 \%)$ cases and 4(9.5\%) in the control group were from upper 
socioeconomic class. In the upper middle class there were $8(19.0 \%)$ cases in study group and $10(23.8 \%)$ cases in the control group. $13(30.9 \%)$ cases in the study group and
$15(35.7 \%)$ cases in the control group were from lower middle class (Table 1).

Table 1: Demographic distribution of cases and controls.

\begin{tabular}{|c|c|c|c|c|}
\hline \multirow{2}{*}{$\begin{array}{l}\text { Demographic variable } \\
\text { Age group }\end{array}$} & \multicolumn{2}{|c|}{ Study group $(n=42)$} & \multicolumn{2}{|c|}{ Control group $(n=42)$} \\
\hline & $\mathrm{N}=42$ & $\%$ & $\mathrm{~N}=42$ & $\%$ \\
\hline $16-20$ & 4 & 10 & 3 & 7 \\
\hline $21-25$ & 15 & 36 & 16 & 38 \\
\hline $26-30$ & 17 & 40 & 20 & 48 \\
\hline $31-35$ & 6 & 14 & 3 & 7 \\
\hline Total & 42 & & 42 & \\
\hline Mean & $25.88=$ & & $25.7 \pm$ & \\
\hline \multicolumn{5}{|l|}{ Gravida } \\
\hline G1 & 17 & 40 & 15 & 35 \\
\hline $\mathrm{G} 2$ & 8 & 20 & 11 & 27 \\
\hline G3 & 11 & 27 & 10 & 23 \\
\hline G4 & 5 & 13 & 4 & 10 \\
\hline$>\mathrm{Gs}$ & 1 & 2 & 2 & 5 \\
\hline Total & 42 & & 42 & \\
\hline Mean & $2.1 \pm 1.2$ & & $2.2 \pm 1$ & \\
\hline \multicolumn{5}{|l|}{ Residential area } \\
\hline Urban & 23 & 55 & 20 & 48 \\
\hline Rural & 19 & 45 & 22 & 52 \\
\hline \multicolumn{5}{|l|}{ Educational status } \\
\hline Literate & 32 & 76.1 & 28 & 66.6 \\
\hline Illiterate & 10 & 23.8 & 14 & 33.3 \\
\hline \multicolumn{5}{|l|}{ Socioeconomic status } \\
\hline Upper & 6 & 14.2 & 4 & 9.5 \\
\hline Upper middle & 8 & 19.0 & 10 & 23.8 \\
\hline Lower middle & 13 & 30.9 & 15 & 35.7 \\
\hline Upper lower & 10 & 23.8 & 8 & 19.0 \\
\hline Lower & 5 & 11.9 & 5 & 11.9 \\
\hline
\end{tabular}

Table 2: Distribution factors associated to gestation of cases and controls.

\begin{tabular}{|c|c|c|c|c|}
\hline \multirow{2}{*}{$\begin{array}{l}\text { Factors } \\
\text { POG (weeks) }\end{array}$} & \multicolumn{2}{|c|}{ Study group } & \multicolumn{2}{|c|}{ Control group } \\
\hline & $\mathbf{N}$ & $\%$ & $\mathbf{N}$ & $\%$ \\
\hline$<28$ & 5 & 11.90 & 6 & 14.29 \\
\hline $28-30$ & 12 & 28.57 & 10 & 23.33 \\
\hline $31-33$ & 10 & 23.33 & 10 & 23.33 \\
\hline $34-36$ & 13 & 30.95 & 14 & 33.33 \\
\hline$>37$ & 2 & 4.76 & 2 & 4.76 \\
\hline Mean & \multicolumn{2}{|c|}{$32.26 \pm 3.037$} & \multicolumn{2}{|c|}{$32.66 \pm 2.817$} \\
\hline \multicolumn{5}{|c|}{ Previous obstetric history } \\
\hline Abortion & 5 & 20 & 4 & 14.81 \\
\hline IUGR & 4 & 16 & 5 & 18.5 \\
\hline Stillbirth & 5 & 20 & 3 & 11.11 \\
\hline None & 11 & 44 & 15 & 55.55 \\
\hline \multicolumn{5}{|c|}{ Difference in SFH (cm) } \\
\hline$<4$ & 27 & 64.29 & 31 & 73.81 \\
\hline$>4$ & 15 & 35.71 & 11 & 26.19 \\
\hline \multicolumn{5}{|c|}{ Difference in abdominal girth (inches) } \\
\hline$\geq 3$ & 17 & 70.3 & 19 & 72.3 \\
\hline$>3$ & 8 & 29.6 & 7 & 27.6 \\
\hline
\end{tabular}


Table 3: Umbilical artery S/D ratio at various gestational period pre- and post-2 hours of sildenafil administration study group.

\begin{tabular}{|c|c|c|c|c|}
\hline \multirow{2}{*}{ Period of gestation (weeks) } & \multirow{2}{*}{ No. of cases } & \multicolumn{2}{|c|}{ Umbilical artery S/D ratio } & \multirow[t]{2}{*}{ P-value } \\
\hline & & Pre-treatment & 2 hours after sildenafil & \\
\hline \multirow[t]{6}{*}{$<28$} & 5 & 6.71 & 5.92 & \\
\hline & & 6.23 & 6.00 & \\
\hline & & 6.51 & 6.31 & \\
\hline & & 7.23 & 6.91 & \\
\hline & & 6.92 & 6.44 & \\
\hline & Mean & $6.72 \pm 0.382$ & $6.316 \pm 0.395$ & 0.0202 \\
\hline \multirow[t]{13}{*}{$28-30$} & 12 & 5.19 & 5.01 & \\
\hline & & 5.175 & 5.23 & \\
\hline & & 5.13 & 4.99 & \\
\hline & & 5.4 & 5.21 & \\
\hline & & 5.31 & 5.32 & \\
\hline & & 5.27 & 5.04 & \\
\hline & & 4.38 & 4.16 & \\
\hline & & 5.42 & 5.72 & \\
\hline & & 5.37 & 5.03 & \\
\hline & & 4.27 & 3.97 & \\
\hline & & 5.19 & 5.10 & \\
\hline & & 5.32 & 5.04 & \\
\hline & Mean & $5.12 \pm 0.383$ & $4.98 \pm 0.48$ & 0.0265 \\
\hline \multirow[t]{11}{*}{$31-33$} & 10 & 4.07 & 4.02 & \\
\hline & & 4.15 & 4.03 & \\
\hline & & 6.34 & 6.38 & \\
\hline & & 7.2 & 7.23 & \\
\hline & & 5.34 & 5.14 & \\
\hline & & 5.61 & 5.32 & \\
\hline & & 4.18 & 4.08 & \\
\hline & & 4.28 & 4.23 & \\
\hline & & 7.4 & 7.42 & \\
\hline & & 4.92 & 4.65 & \\
\hline & Mean & $5.35 \pm 1.27$ & $5.25 \pm 132$ & 0.0291 \\
\hline \multirow[t]{14}{*}{$34-36$} & 13 & 6.2 & 6.24 & \\
\hline & & 5.76 & 5.54 & \\
\hline & & 5.34 & 5.24 & \\
\hline & & 5.21 & 5.05 & \\
\hline & & 4.38 & 4.16 & \\
\hline & & 4.40 & 4.22 & \\
\hline & & 4.18 & 4.03 & \\
\hline & & 4.27 & 4.07 & \\
\hline & & 4.51 & 4.32 & \\
\hline & & 5.34 & 5.37 & \\
\hline & & 5.82 & 5.88 & \\
\hline & & 6.41 & 6.43 & \\
\hline & & 4.73 & 4.53 & \\
\hline & Mean & $5.12 \pm 0.76$ & $5.01 \pm 0.85$ & 0.003 \\
\hline \multirow[t]{3}{*}{$>37$} & 2 & 4.2 & 3.87 & \\
\hline & & 5.13 & 4.76 & \\
\hline & Mean & $4.67 \pm 0.66$ & $4.32 \pm 0.63$ & 0.018 \\
\hline
\end{tabular}

In the study group, $5(11.9 \%)$ cases were of less than 28 weeks gestation while $6(14.29 \%)$ cases in the control group were less than 28-week, gestational period. Among the study group. $12(28.57 \%)$ belonged to $28-30$ weeks gestational group whereas, in the same gestational group there were $10(23.33 \%)$ cases in the control group. In the 
31-33 weeks gestational age group $10(23.33 \%)$ cases were included in both study and control groups. 13 $(30.95 \%)$ cases; in the study group and 14 (33.33\%) cases in the control group were in 34-36 gestational age group. Only $2(4.76 \%)$ cases in both the groups were $>37$ weeks of gestational age. The mean gestational age of study group was $32.26 \pm 3.037$ and of control group was $32.66 \pm 2.817$. There were 17 primigravidae in the study group and 15 primigravidae in the control group; Excluding these, other antenatal women were classified based on their previous obstetric history if it was abortion, IUGR, stillbirth or none i.e., no significant previous obstetric history. Few cases had more than one previous significant obstetric history in both the groups. 5 (20\%) cases in the study group and $4(14.81 \%)$ had a previous history of abortion. $4(16 \%)$ cases in the study group and $5(18.5 \%)$ cases in the control group had IUGR in their previous pregnancy. In the study group, 5 (20\%) cases and in the control group $3(11.11 \%)$ cases had a previous history of stillbirth. Others i.e. $11(44 \%)$ cases in the study group and $15(55.55 \%)$ cases in the control group had no significant previous obstetric history. The discrepancy in symphysiofiindal height of $<4 \mathrm{~cm}$ was present in about $27(64.29 \%)$ cases in the study group and in $31(73.81 \%)$ cases in the control group. Discrepancy of $>4 \mathrm{~cm}$ was present in $15(35.71 \%)$ cases in the study group while the same discrepancy in the control group was present in $11(26.19 \%)$ cases. Abdominal girth is measured after 30 weeks. Hence out of 42 cases in each group, abdominal girth of the woman was measured in 25 cases in the study group and in 26 cases in the control group. In the study group $17(70.3 \%)$ cases had a difference of abdominal girth $<3$ inches and $8(29.6 \%)$ cases had difference of $>3$ inches. In the control group abdominal girth difference $<3$ inches was present in 19 $(72.3 \%)$ cases and difference of $>3$ Inches was present in $7(27.6 \%)$ cases (Table 2).

All 5 cases $<28$ weeks gestation showed a decrease in umbilical artery S/D ratio 2 hours after $50 \mathrm{mg}$ sildenafil administration which was statistically significant $(p=0.0202)$. Mean $S / D$ ratio in the study group was $6.72 \pm 0.382$ and in the post 2 hours group was $6.316 \pm 0.395$. in the $28-30$ weeks gestational age group, out of 12 cases given sildenafil, 3 showed an increase in S/D ratio of umbilical artery after 2 hours while other 9 cases demonstrated a fell in S/D ratio. Mean S/D ratio pre-treatment was $5.12 \pm 0.383$ which 2 hours after sildenafil administration became 4.98 \pm 0.48 . This difference in S/D ratio was clinically significant $(p=0.0265)$. Out of 10 cases in the 31-33 weeks group, 3 showed an increase in S/D ratio whereas other 7 cases demonstrated a favourable decrease in this ratio. Mean $\mathrm{S} / \mathrm{d}$ ratio in the pre-treatment group was $5.35 \pm 1.27$ and in post-sildenafil administration group was $5.25 \pm 1.32$. this difference in S/D ratio was found to be statistically significant $(p=0.0291)$. Cases with gestational ages between 34-36 showed a decrease in the umbilical artery S/D ratio in 9 out of 13 cases. In the remaining 4 cases sildenafil administration failed to show a decrease, instead showed a slight increase in this ratio. Mean S/D ratio was $5.11 \pm 0.76$ before sildenafil which decreased to $5.01 \pm 0.85$. The overall difference was statistically significant $(\mathrm{p}=.003)$. Of the two patients $>37$ weeks gestation, both of them showed decrease in S/D ratio of umbilical artery. The mean S/D ratio decreased from $4.67 \pm 0.66$ to $4.32 \pm 0.63$ after 2 hours of sildenafil, which was significant statistically $(\mathrm{p}=0.018)$. the overall mean $\mathrm{S} / \mathrm{D}$ ratio pre-sildenafil was $5.34 \pm 0.93$ which reduced to $5.18 \pm 0.95$ after 2 hours of sildenafil administration and this significant was highly significant $(\mathrm{p}<0.0001)$ (Table 3).

There were 6 cases in the control group <28 weeks gestation who were administered placebo and their Doppler repeated after 2 hours. 4 cases showed an increase in S/D ratio while 2 of them showed a slight decrease in this ratio. The differences between the mean $\mathrm{S} / \mathrm{D}$ ratios, that is $6.50 \pm 0.47$ and $6.51 \pm 0.52$ was statistically insignificant $(\mathrm{p}=0.99)$. Cases in $28-30$ weeks gestational period which underwent Doppler before and after placebo administration showed a decrease in only 1 case while 8 of them showed increase in S/D ratio. 1 case did not demonstrate any change in the S/D ratio. The mean S/D ratio changed from $5.55 \pm 0.397$ to $5.58 \pm 0.43$ and the difference between them was not significant statistically $(\mathrm{p}=0.85)$. There were 10 cases in 31-33 weeks gestational age group of which in only 3 cases S/D ratio decreased, in 1 case it remained the same and in remaining 7 it increased. The mean S/D ratio was $6.04 \pm 0.76$ in the pre-treatment group which increased to $6.03 \pm 0.772$ hours after placebo. The difference between them was also not significant statistically ( $\mathrm{p}=0.99)$. 34-36 weeks gestational age group consisted of 14 cases in which S/D ratio decreased in only 2 cases and char too only marginally. In others it decreased. The mean decrease in the S/D ratio was from $5.04 \pm 0.76$ to $5.06=$ : 0.78 which was not significant statistically $(\mathrm{p}=0.95)$. There were two cases $>37$ weeks of gestation both of which showed an increase in their S/D ratios. Their mean $\mathrm{S} / \mathrm{D}$ ratio were $4.86 \pm 0.61$ and $4.96 \pm 0.66$ respectively. This difference was, however, not statistically significant $(\mathrm{p}=0.89)$. The mean umbilical artery $\mathrm{S} / \mathrm{D}$ ratio before placebo administration in the control group was $5.598 \pm 0.83$ and $5.617 \pm 0.832$ hours after giving- placebo. The difference between them was found to be insignificant statistically $(\mathrm{p}=0.914)$ (Table 4).

Only 5 cases in the study group received sildenafil $25 \mathrm{mg}$ for a total period of 12 weeks. When these cases were followed up after 12 weeks with umbilical artery Doppler, 4 of them demonstrated a decrease in their umbilical artery S/D ratios. Only one case demonstrated an absent umbilical artery diastolic flow at the end of 12 weeks. The mean S/D ratio pre-treatment was $6.72 \pm 0.38$ which decreased to $3.52 \pm 0.4712$ weeks after sildenafil administration. The difference between them was found to be extremely significant $(\mathrm{p}<0.0001)$ (Table 5). 
Table 4: Umbilical artery S/D ratio at various gestational period pre- and post-2 hours of placebo administration control group.

\begin{tabular}{|c|c|c|c|c|}
\hline \multirow{2}{*}{ Period of gestation (weeks) } & \multirow{2}{*}{ No. of cases } & \multicolumn{2}{|c|}{ Umbilical artery S/D ratio } & \multirow{2}{*}{ P-value } \\
\hline & & Pre treatment & 2 hours after placebo & \\
\hline \multirow[t]{6}{*}{$<28$} & 6 & 6.17 & 6.18 & \\
\hline & & 6.34 & 6.38 & \\
\hline & & 6.71 & 6.73 & \\
\hline & & 5.97 & 5.87 & \\
\hline & & 7.3 & 7.40 & \\
\hline & & 6.51 & 6.47 & \\
\hline . & Mean & $6.50 \pm 0.47$ & $6.51 \pm 0.52$ & 0.99 \\
\hline \multirow[t]{11}{*}{$28-30$} & 10 & 5.17 & 5.19 & \\
\hline & & 5.43 & 5.44 & \\
\hline & & 5.29 & 5.29 & \\
\hline & & 5.72 & 5.71 & \\
\hline & & 5.40 & 5.42 & \\
\hline & & 6.20 & 6.32 & \\
\hline & & 6.30 & 6.38 & \\
\hline & & 5.31 & 5.37 & \\
\hline & & 5.38 & 5.43 & \\
\hline & & 5.28 & 5.29 & \\
\hline & Mean & $5.55 \pm 0.397$ & $5.58 \pm 0.43$ & 0.85 \\
\hline \multirow[t]{11}{*}{$31-33$} & 10 & 5.30 & 5.32 & \\
\hline & & 5.21 & 5.22 & \\
\hline & & 5.72 & 5.67 & \\
\hline & & 6.34 & 6.34 & \\
\hline & & 7.20 & 7.23 & \\
\hline & & 7.30 & 7.31 & \\
\hline & & 5.82 & 5.80 & \\
\hline & & 6.34 & 6.37 & \\
\hline & & 5.93 & 5.87 & \\
\hline & & 5.21 & 5.22 & \\
\hline & Mean & $6.04 \pm 0.76$ & $6.03 \pm 0.77$ & 0.99 \\
\hline \multirow[t]{15}{*}{$34-36$} & 14 & 5.34 & 5.32 & \\
\hline & & 6.40 & 6.42 & \\
\hline & & 5.45 & 5.65 & \\
\hline & & 3.19 & 3.18 & \\
\hline & & 5.48 & 5.51 & \\
\hline & & 4.98 & 4.99 & \\
\hline & & 4.73 & 4.82 & \\
\hline & & 5.38 & 5.39 & \\
\hline & & 5.92 & 5.93 & \\
\hline & & 4.94 & 4.98 & \\
\hline & & 4.56 & 4.64 & \\
\hline & & 4.29 & 4.31 & \\
\hline & & 4.72 & 4.68 & \\
\hline & & 5.16 & 5.17 & \\
\hline & Mean & $5.04 \pm 0.76$ & $5.06 \pm 0.78$ & 0.95 \\
\hline \multirow[t]{3}{*}{$\geq 37$} & 2 & 4.43 & 4.49 & \\
\hline & & 5.3 & 5.43 & \\
\hline & Mean & $4.86 \pm 0.61$ & $4.96 \pm 0.66$ & 0.89 \\
\hline
\end{tabular}

In the control group, 6 eases were followed at the end of 12 weeks with umbilical artery S/D ratio. Of the 6 cases, only 3 cases demonstrated a decrease in S/D ratios, 2 of them showed absent diastolic flow and one of them showed reversed end-diastolic flow in the umbilical artery at the end of 12 weeks (Table 6). 
Table 5: Umbilical artery S/D ratio at various gestational period pre- and post-treatment (12 weeks) sildenafil study group.

\begin{tabular}{|c|c|c|c|}
\hline \multirow{2}{*}{$\begin{array}{l}\text { Period of } \\
\text { gestation } \\
\text { (weeks) }\end{array}$} & \multicolumn{3}{|c|}{ Umbilical artery S/D ratio } \\
\hline & No. & $\begin{array}{l}\text { Pre- } \\
\text { treatment }\end{array}$ & $\begin{array}{l}\text { After } 12 \text { weeks } \\
\text { of sildenafil }\end{array}$ \\
\hline \multirow[t]{6}{*}{$<28$} & 5 & 6.71 & 3.14 \\
\hline & & 6.23 & 3.62 \\
\hline & & 6.51 & 3.18 \\
\hline & & 7.23 & A \\
\hline & & 6.92 & 4.14 \\
\hline & Mean & $6.72 \pm 0.38$ & $3.52 \pm 0.47$ \\
\hline
\end{tabular}

Table 6: Umbilical artery $S / D$ ratio at various gestational period pre- and post-treatment ( 12 weeks) control group.

\begin{tabular}{|c|c|c|c|}
\hline \multirow{2}{*}{$\begin{array}{l}\text { Period of } \\
\text { gestation } \\
\text { (weeks) }\end{array}$} & \multicolumn{3}{|c|}{ Umbilical artery S/D ratio } \\
\hline & No. & $\begin{array}{l}\text { Pre- } \\
\text { treatment }\end{array}$ & $\begin{array}{l}\text { After } 12 \text { weeks } \\
\text { of placebo }\end{array}$ \\
\hline \multirow[t]{7}{*}{$<28$} & 6 & 6.17 & 4.33 \\
\hline & & 6.34 & A \\
\hline & & 6.71 & $\mathrm{R}$ \\
\hline & & 5.97 & 4.76 \\
\hline & & 7.3 & A \\
\hline & & 6.51 & 4.78 \\
\hline & Mean & $6.5 \pm 0.47$ & $4.62 \pm 0.25$ \\
\hline
\end{tabular}

\section{DISCUSSION}

Fetal growth restriction is defined as a pathologic decrease in the rate of fetal growth. Excluding fetal anomalies, after prematurity fetal growth restriction (FGR) is the second common cause of perinatal morbidity. FGR should be diagnosed in the presence of any of the factors associated with a poorer perinatal outcome, including Doppler cerebroplacental ratio, uterine artery Doppler, a growth centile below the $3^{\text {rd }}$ centilc, and, possibly in the near future, maternal angiogenic factors. Consequent to the uteroplacental vascular maladaptation of endovascular trophoblastic invasion, there is increased vascular resistance and decreased blood flow to the placenta in the choriodecidual compartment. In a normal pregnancy, the trophoblast produces nitric oxide (NO) which plays an important role in vasodilatation in the fetoplacental circulation to improve oxygen and nutritional supply to the fetus (Rosselli et al, Ramsavet al). ${ }^{10,11}$ Antenatal women between gestational age 24-37 weeks with clinical or ultrasonographic evidence of fetal growth restriction were selected for the present study. The cases in the study group underwent colourdoppler and then were given oral sildenafil citrate $50 \mathrm{mg}$ stat followed by a repeat colour Doppler 2 hours later to visualise the shortterm effect of sildenafil on S/D ratio of umbilical artery.
The cases in the study group were then given oral sildenafil $25 \mathrm{mg}$ thrice daily for a period of 12 weeks.

\section{Demographical distribution of cases and controls}

In this study, the cases were divided into 4 groups according to age of antenatal women included. The mean age of study group was $25.88 \pm 4.145$ and the mean age of control group was $25.7 \pm 3.623$. The difference between the two group was statistically insignificant. It was seen that age, by itself, is not an important contributor of fetal growth restriction. It was thus concluded that age does not play any significant part in its occurrence along with fetal growth restriction. The only correlation could be seen was of occurrence of FGR in association with hypertensive disorders which may occur more with advancing age. Similarly, Dastjerdi et al studied the cases while keeping the maternal age between the two groups similar as in present study. ${ }^{8}$ In their study, similar to present study the mean age was $25.64 \pm 1.5$ in the sildenafil-treated group and $32.0 \pm 0.2$ in the sildenafilnaive group. This difference was not significant $(\mathrm{p}=0.39)$. As literate women seek for antenatal advice early in pregnancy and come for antenatal supervision, hence fetal growth restriction in these cases is diagnosed timely. The distribution among other groups was less distinct non-significant. This shows that, a part from socioeconomic status, other factors are also operative in causing total growth restriction. Socioeconomic stains play an indirect role via nutritional status. These reasons predispose them to poor health status in pre-pregnancy as well as pregnancy period, leading to fetal growth restriction.

\section{Distribution factors associated to gestation of cases and controls}

The mean period of gestation of the study group was $32.36 \pm 3.037$ and that of the control group was $32.66 \pm 2.817$ and the difference was statistically insignificant. Similarly, Dastjerdi et al also found that the mean gestational age in weeks of the study group and control group each and the $\mathrm{p}$ value was $0.86 .^{8}$ The difference was not significant as demonstrated in the present study. Almost similar was the observation of Dadelszenet al who studied women with fetal growth restriction and the mean gestational age at eligibility of the two groups were 21 weeks and 22 weeks respectively. ${ }^{12}$ However, the difference between the two groups was not significant $(\mathrm{p}=0.15)$ similar to present study. Almost half of the cases had no significant previous obstetric history in the study group (44\%) so also in the control group (55\%). This study could not correlate occurrence of fetal growth restriction in present pregnancy with previous obstetric history. In the present study, clinically fetal growth restriction was identified by several factors including discrepancy in symphysiofundal height. 
Although there are a number of other reasons for this discrepancy including mistaken dates, oligohydramnios transverse lie, engaged head and small for gestational age a difference between symphysiofundal height and gestational age of $>4 \mathrm{~cm}$ was more predictive of FGR. This difference too was statistically insignificant. The mean S/D ratio before sildenafil administration in present study was $5.34 \pm 0.93$ and that in the same group 2 hours after sildenafil $50 \mathrm{mg}$ oral administration was 5.18 \pm 0.95 . This difference was found to be statistically significant $(p<0.0001)$. The $S / D$ ratio was determined in the umbilical artery of all cases across all gestational age groups and the mean S/D ratio between the two groups before and after sildenafil administration was found to be significant in all of them. This finding is consistent with the mechanism of action of sildenafil which vasodilates the myometrial vessels, thus enhancing the end- diastolic flow which in turn decreases the S/D ratio. Sildenafil 50 mg was associated with significant changes in the fetoplacental Doppler flow velocimetry waveforms as compared to controls. This hypothesis stems from the similarities between the pathophysiology associated with preeclampsia and FGR due to a relative placental hypoperfusion. The similar observations in the control group who were given placebo failed to show any significant decrease in mean $\mathrm{S} / \mathrm{D}$ ratio after 2 hours $(p=0.914)$. Mean umbilical artery S/D ratio in the pretreatment study group was $5.34 \pm 0.93$ while that of control group was $5.598 \pm 0.83$ and this difference was seen to be clinically non-significant $(\mathrm{P}$ value $=0.188) .2$ hours after sildenafil administration the mean S/B ratio became $5.18 \pm 0.95$ and that of control group after giving placebo was $5.617 \pm 0.83$. The difference between these groups was significant statistically (p-0.026). In the Dastjerdi et al study, 41 pregnant women with documented intrauterine growth retardation at 24-37 weeks of gestation were evaluated for the effect of a single dose of Sildenafil citrate on uteroplacental circulation as determined by Doppler ultrasound study of the umbilical and middle cerebral arteries. ${ }^{8}$

The mean S/D ratio in umbilical artery before and after 2 hours of sildenafil $50 \mathrm{mg}$ were $3.26 \pm 0.54$ and $2.66 \pm 0.33$ respectively and this difference was significant $(\mathrm{p}=0.000)$ but not in the other group which received only placebo $(\mathrm{p}=0.22)$. Only remaining 5 cases were subjected to colour Doppler of umbilical artery at the end of the study. Mean S/D ratio in the pre-treatment group of present study was $6.72 \pm 0.38$ while that 12 weeks after $25 \mathrm{mg}$ thrice daily sildenafil administration at the end of the study was $3.52 \pm 0.47$. This difference was found to be highly significant $(\mathrm{p}<0.001)$. In the Cottrell et al study, NO was found to vasodilator in both the maternal resistance vessels controlling blood flow to the placenta as well as in the fetoplacental resistance vessels and there is considerable evidence for reduced production and/or liioavailability of NO in both FGR and pre-eclampsia. ${ }^{13}$ Originally developed to treat pulmonary hypertension, SC acts by inhibiting rhcphoshodicstcrasc (PDE) type 5 enzyme which catalyses the breakdown of cyclic GMP, prolonging the actions of NO throughout the body and enhancing NO-dependent vasodilation.

\section{CONCLUSION}

The present study concluded that the difference between study and control group regarding age, gravidity, habitat, educational and socioeconomic status, mean gestational age, amniotic fluid index, body mass index, previous obstetric history, discrepancy in symphysiofundal height and abdominal girth were not significant. However, there were statistical differences between the two groups in terms of mean umbilical artery S/D ratio, before and after 2 hours of sildenafil administration. Sildenafil helped improve the mean gestational age in the study group as compared to that in the control group treated with placebo, but the increase was not significant. Sildenafil therapy was associated with a lower rate of caesarean sections. Sildenafil, as a vasodilator, could be an alternative in the treatment of Intra Uterine Growth Retardation (IUGR) and preeclampsia by later normalization in velocimetric profile. Treatment with sildenafil citrate in the last third of gestation counteracts fetal growth retardation by favouring placental development and function and, thus, fetal growth. Administration of sildenafil citrate may have a potential benefit in pregnancies complicated by placental insufficiency and IUGR.

Funding: No funding sources Conflict of interest: None declared

Ethical approval: The study was approved by the Institutional Ethics Committee

\section{REFERENCES}

1. Lang U, Baker RS, Braems G, Zygmunt M, Kunzel W, Clark KE. Uterineblood flow: a determinant of fetal growth. Eur J ObstetGynecol. 2003;110 (Suppl 1):S55-S61.

2. Petersen SG, Wong SF, Urs P, Gray PH, Gardener GJ. Early onset, severe fetal growth restriction with absent or reversed end-diastolic flow velocity waveform in the umbilical artery: perinatal and long-term outcomes. Aust NZ J Obstet Gynaecol. 2009;49:45-51.

3. Baschat AA. Doppler application in the delivery timing of the preterm growth-restricted fetus: another step in the right direction. Ultrasound Obstet Gynecol. 2004;23:111-8.

4. Wareing M, Myers JE, O'Hara M, Baker PN. Sildenafil citrate (Viagra) enhances vasodilatation in fetal growth restriction. J Clin Endocrinol Metab. 2005;90:2550-5.

5. Zoma WD, Baker RS, Clark KE. Effects of combined use of sildenafil citrate (Viagra) and 17 beta-estradiol on ovine coronary and uterine hemodynamics. Am J Obstet Gynecol. 2004;190:1291-7. 
6. Panda, S, Das, A, Md Nowroz H. Sildenafil citrate in fetal growth restriction. J Reprod Infertil. 2014;15:168-9.

7. Dilworth MR, Andersson I, Renshall LJ, Cowley E, Baker P, Greenwood S, et al. Sildenafil citrate increases fetal weight in a mouse model of fetal growth restriction with a normal vascular phenotype. PLoS One. 2013;8(10):7774-8.

8. Dastjerdi MV, Hosseini S, Bayani L. Sildenafil citrate and uteroplacental perfusion in fetal growth restriction. J Res Med Sci. 2012;17:632-6.

9. Jennifer MS, Chris B. Effects of sildenafil on maternal hemodynamics and fetal growth in normal rat pregnancy. Am J Physiol Regul Integr Comp Physiol. 2010;298:R433-8.

10. Rosselli M, Keller RJ, Dubey RK. Role of nitric oxide in the biology, physiology and pathophysiology of reproduction. Hum Reprod Update. 1998;4:23-4.
11. Ramsay B, Sooranna SR, Johnson MR. Nitric oxide synthase activities in human myometrium and villous trophoblast throughout pregnancy. Obstet Gynecol. 1996;87:249-53.

12. von Dadelszen P, Magee LA, Lee SK, Stewart SD, Simone C, Koren G, et al. Activated protein C in normal human pregnancy and pregnancies complicated by severe preeclampsia: a therapeutic opportunity?. Crit Care Med. 2002;30:1883-92.

13. Cottrell EC, Sibley CP. From pre-clinical studies to clinical trials: generation of novel therapies for pregnancy complications. Int $\mathrm{J}$ Mol Sci. 2015; 16:12907-24.

Cite this article as: Singh $\mathrm{P}$, Saiyda $\mathrm{H}$. Sildenafil citrate and uteroplacental perfusion in fetal growth restriction. Int J Reprod Contracept Obstet Gynecol 2018;7:5116-24. 